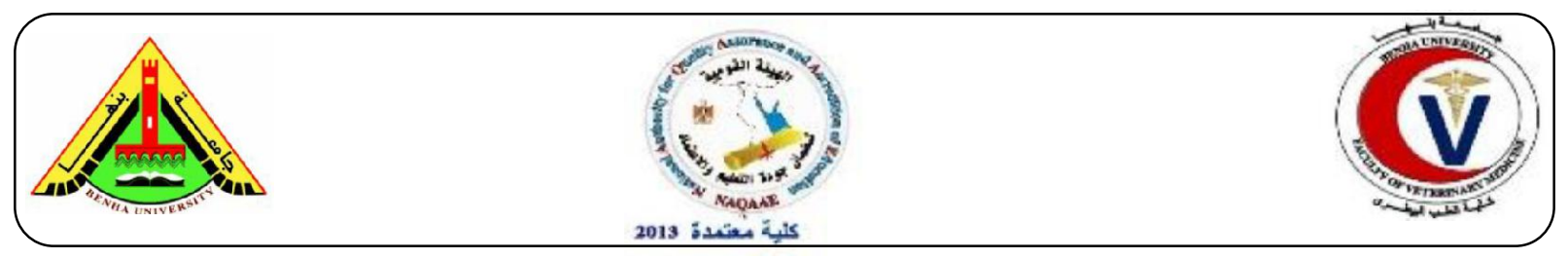

\title{
Assessment of protective potential of Quercitin against carbendazim-induced testicular damage in male rats
}

\author{
Omayma A.R. Abou Zaid'; Ahmed A.El saed²; Abeer M.S. Elbatal ${ }^{1}$ \\ ${ }^{1}$ Department of Biochemistry, Faculty of Veterinary Medicine, Benha University \\ ${ }^{2}$ Department of Histology, Faculty of Veterinary Medicine, Zagazig University
}

\section{A B S T R A C T}

Quercetin (Q) is a common flavonoid, with potent anti-inflammatory and antioxidant activities. However, its protective role against the hazards of fungicides has been poorly studied. Therefore, the present work aimed at determining the ameliorative potential of Q against testicular damage induced by carbendazim (CBZ) in male rats. In CBZ-induced testicular damage rats treated with quercetin, it was demonstrated that the activities of the antioxidant enzymes superoxide dismutase (SOD) and glutathione content (GSH) were increased, malondialdehyde (MDA) was inhibited, and interleukin (IL)-1 $\beta$, IL-6, Tumor necrosis factor- $\alpha$ (TNF- $\alpha$ ) were suppressed. Quercetin additionally enhanced testosterone and cyclic guanine monophosphate (cGMP) levels. These results suggested that the protective role of quercetin prevents CBZ-induced testicular damage through the free radical scavenging activities, preventing pro-inflammatory cytokine production and improving the male reproductive markers.

Keywords: Quercetin, CBZ, cGMP, Testicular damage, Oxidative stress.

(http://www.bvmj.bu.edu.eg) (BVMJ-34(2): 305-320, 2018)

\section{INTRODUCTION}

Toxicology of the male reproductive system has received increasing interest because a significant deterioration in the quality of sperm has been observed in industrialized countries over the past 50 years (Carlsen et al., 1992;
Geoffroy-Siraudin et al., 2012a; Le Moal et al., 2014). Environmental chemicals, among them pesticides, have been implicated in this deterioration (Chiu et al., 2015; Mehrpour et al., 2014). Moreover, semen quality may be a 
fundamental biomarker of overall male health

(Eisenberg et al., 2014; Jensen et al., 2009).

The widespread use of pesticides in agriculture may result in contamination of surface water and consequently pose a permanent risk to a range of non-target aquatic organisms including fish (Guo et al., 2008). Carbendazim (CBZ) is a widely used benzimidazole fungicide in agriculture for pre- and postharvest treatment in control of various pathogens (Selmanoglu et al., 2001). Previous studies have showed that carbendazim could disrupt various aspects of reproductive system, cause germ cell apoptosis, embryotoxicity, or teratogenesis in hamsters, mice, rats or human

(Adedara et al., 2013; Akbarsha et al., 2001; Carter et al., 1987; Farag et al., 2011; Mantovani et al., 1998; Morinaga et al., 2004; Yu et al., 2009; Zhou et al., 2015). In addition, carbendazim is extremely toxic to fish and other aquatic organisms (Boudina et al., 2003; Palanikumar et al., 2014; Ludwikowska et al., 2013).

Carbendazim (Methyl-1H-Benzimidazol-2ylcarbamate) is a stable benzimidazole fungicide widely used to control fungal disease; however, stability and soil persistence can lead to long-term contamination, as its chemical structure favors adsorption into the soil matrix and accumulation following repeated applications (Lewandowska and Walorczyk, 2010). CBZ is also reported to disrupt the human endocrine system and contribute to serious estrogen-mediated pathologies (Morinaga et al., 2004), as well as damage the mammalian liver, endocrine, and reproductive tissues even at low doses (Zhang et al., 2013). Moreover, the persistence of $C B Z$ in soil alters the biodiversity of bacterial communities and adversely affects microbial functions (Singh et al., 2016; Wang et al., 2009). The half-life of $C B Z$ ranges from several days to 12 months depending on the nature of the soil (Singh et al., 2016).

Flavonoids beneficially affect human and animal health. As a typical flavonol-type flavonoid, quercetin is ubiquitously present in fruits and vegetables and is considered a strong antioxidant because of its ability to scavenge free radicals and bind to transition metal ions; as such, this flavonoid participates in multiple pharmacological activities, including antiinflammation, platelet aggregation prevention, and antitumor effects (Phan et al., 2004; de Souza and De Giovani, 2004; Iskender et al., 2017; Thipkaew et al., 2017; Roslan et al., 2017).

Quercetin is one of the widely distributed flavonoids in the plant kingdom. It exists richly and extensively in human diet, including fruits, vegetables, tea, red wine and diverse food supplements (Marunaka, 2017). It is estimated that quercetin and its relevant derivatives account for nearly $60 \%-70 \%$ of flavonoids intake in human daily life (Liu et al., 2017). Recently, the medicinal properties of quercetin have captured much attention for its powerful biological activities, including anti-inflammation, anti-oxidation, antivirus 
and anti-cancer (Wang et al., 2012; Wu et al., 2015; Rivera Rivera et al., 2016).

Quercetin is a member of the flavonol subclass of flavonoids and is usually present in a glycosylated form (Grande et al., 2016). The major sources of Quercetin are fruits, including apples, berries and cherries, vegetables, including onions and broccoli, and beverages, including red wine and tea (Boots et al., 2008). Quercetin has been also identified in several medicinal plants, such as Ginkgo biloba, Aesculus hippocastanum and Hypericum perforatum (Grande et al., 2016). Quercetin has been applied in various fields, due to its anti-inflammatory, antiviral, anti-allergy, antioxidant, anti-asthmatic and antitumor activities (Brito et al., 2015). This study was conducted to examine the effects of carbendazim on testis and the possible ameliorative role of quercetin in albino rat.

\section{Materials and methods}

\subsection{Animals:}

Sexually mature male albino Wistar rats weighing $150 \pm 10 \mathrm{~g}$ were used in this study. Animals were kept in the laboratory under constant temperature $\left(24 \pm 2{ }^{\circ} \mathrm{C}\right)$ throughout the experimental work. They were maintained on a standard rodent diet composed of $20 \%$ casein, $15 \%$ corn oil, $55 \%$ corn starch, $5 \%$ salt mixture, and $5 \%$ vitaminized starch (Egyptian Company of Oils and Soap, KafrElzayat, Egypt). Water was available ad libitum. Maintenance of animals and experimental procedures was approved by the animal ethical committee in accordance with the guide for care and use of laboratory animals of Menoufiya University, Egypt.

\subsection{Materials:}

Carbendazim (methyl-2-benzimidazole carbamate) was obtained from Kafr El-Zayat Pesticides \& Chemicals Company, Egypt (Kafer El-Zayat, Gharbia). It was freshly prepared in corn oil and orally administrated. Quercetin was purchased from Sigma Chemical Co. (St Louis, MO, USA).

\subsection{Treatments:}

Animals were divided into four groups:

Group 1: These animals (10 rats) served as controls and were given corn oil additionally to their food.

Group 2: Animal of this group (10 rats) has been orally given $0.1 \mathrm{ml}$ of corn oil comprising $300 \mathrm{mg} / \mathrm{kg}$ body weight carbendazim for 3 days weekly for 8 weeks (Songür et al., 2005).

Group 3: Animal of this group (10 rats) have been injected intragastric with quercetin (150 $\mathrm{mg} / \mathrm{kg}$ ) for 3 days weekly for 2 weeks followed by giving $0.1 \mathrm{ml}$ of corn oil comprising 300 $\mathrm{mg} / \mathrm{kg}$ body weight carbendazim for 3 days weekly for 6 weeks (Songür et al., 2005).

Group 4: Animals of this group (10 rats) have been orally given carbendazim $(300 \mathrm{mg} / \mathrm{kg}$ body weight), followed by treatment with quercetin (intragastric injection, $150 \mathrm{mg} / \mathrm{kg}$ ) (Chen et al., 2017) for 3 days weekly for 2 weeks.

\subsection{Tissue processing for histological study:} Immediately after decapitation, testis was dissected removed from treated and control 
animals and fixed in Bouin's solution. After fixation, specimens were dehydrated in an ascending series of alcohol, cleared in two changes of xylene, and embedded in molten paraffin. Sections of $5 \mathrm{~mm}$ thickness were cut using rotary microtome and mounted on clean slides. For histopathological examination, sections were stained with hematoxylin and counter stained with eosin. At least five sections of testicular tissue from each rat were examined in each animal group.

\subsection{Oxidative stress and antioxidant enzymes assays:}

For determination of oxidative stress and antioxidant enzymes in the testes, tissues were homogenized in $0.1 \mathrm{M}$ phosphate buffer $(\mathrm{pH}$ 7.4) using a polytron homogenizer, the homogenate was centrifuged at $18,000 \mathrm{~g}$ for 30 min and the supernatant was utilized for biochemical analysis. The extent of lipid peroxidation (LPO) was estimated as the concentration of thiobarbituric acid reactive products (malondialdehyde, MDA) according to Ohkawa et al. (1979). Superoxide dismutase (SOD) activity was measured using the methods of Rest and Spitznagel (1977). The principle of this method depends on the ability of SOD to inhibit the power of phenazine methosulphate to reduce the nitroblue tetrazolium dye.

\subsection{Assay of the Testicular Glutathione}

\section{Level:}

The level of GSH in the testicular tissue was determined spectrophotometrically according to Jollow et al. (1974). The colored product (2- nitro-5-thiobenzoic acid) produced from the reaction of Ellman's reagent (5,5'-dithiobis-(2nitrobenzoic acid), DTNB) with GSH has a molar absorption at $412 \mathrm{~nm}$.

\subsection{Determination of serum TNF-a, IL-6} and IL-1 $\beta$ by enzyme-linked immunoadsorbent assays (ELISA):

ELISAs of the three cytokines in the serum were performed using kits produced by BioSource International (Camarillo, CA, USA).

\subsection{Determination of serum Testosterone levels:}

Testosterone levels were measured in serum using commercial ELISA kits for endogenous rat testosterone according to the manufacturer's protocol (Cusabio). All of the samples were assayed at the same time. The linear range was $0.13-25.6 \mathrm{ng} / \mathrm{ml}$.

\subsection{Measurement of testis cGMP content:}

Testis tissues obtained from rats were used for the urethral cGMP content determination. The concentration of cGMP was evaluated using a cGMP-EIA kit purchased from Cayman Chemical Company (cat no. 581021; Ann Arbor, MI, USA), according to the manufacturers protocol. The yellow-colored product formed with the EIA is inversely proportional to the amount of cyclic nucleotide present in the sample and was detected at 412 $\mathrm{nm}$ by a plate reader (Victor2 1420; PerkinElmer, Inc., Waltham, MA, USA).

\subsection{Statistical analysis:}

Data are presented as the mean \pm standard deviation. Experiments were performed at 
least in triplicate. Data were analyzed using SPSS 19.0 (IBM Corp., Armonk, NY, USA). One-way analysis of variance followed by an LSD post hoc test was used for inter-group comparisons. $\mathrm{P}<0.05$ was considered to indicate a statistically significant difference.

\section{RESULTS}

\section{Quercetin decreases CBZ-induced oxidative}

damage: To investigate the antioxidant effects of quercetin in CBZ-induced testicular damage in rats, SOD activity, GSH and MDA contents were measured using ELISA Kits. The SOD activity and GSH content were reduced, and MDA content was increased in CBZ model group, compared with control group (Fig. 1). Quercetin significantly increased SOD and GSH content and inhibited MDA content in CBZ model group, compared with CBZ model group (Fig. 1). These data indicate that quercetin might inhibit oxidative stress of CBZ-induced testicular damage.

\section{Quercetin suppresses CBZ-induced} proinflammatory cytokine production:
To investigate the anti-inflammation effects of quercetin in CBZ-induced testicular damage in rats, TNF- $\alpha$, IL- $1 \beta$ and IL-6 contents were measured using ELISA Kits. The levels of TNF- $\alpha$, IL-1 $\beta$ and IL- 6 were promoted in CBZ model group, compared with control group (Fig. 2). Quercetin significantly also reduced TNF- $\alpha$, IL-1 $\beta$ and IL-6 levels in CBZ-treated rats, compared with CBZ model group (Fig. 2). Our study showed that quercetin reduced inflammation of CBZ, and its mechanism need to measure.

\section{Quercetin improves CBZ-induced testicular}

damage: To investigate the protective effects of quercetin in CBZ-induced testicular damage in rats, Testosterone and cGMP levels were measured using ELISA Kits. Serum testosterone and testicular cGMP levels in CBZ-treated rats were significantly inhibited compared to controls. Treatment with Q (50 $\mathrm{mg} / \mathrm{kg} /$ day) to CBZ-treated rats for 2 weeks significantly enhanced to testosterone and cGMP levels compared to their respective controls (Fig. 3).

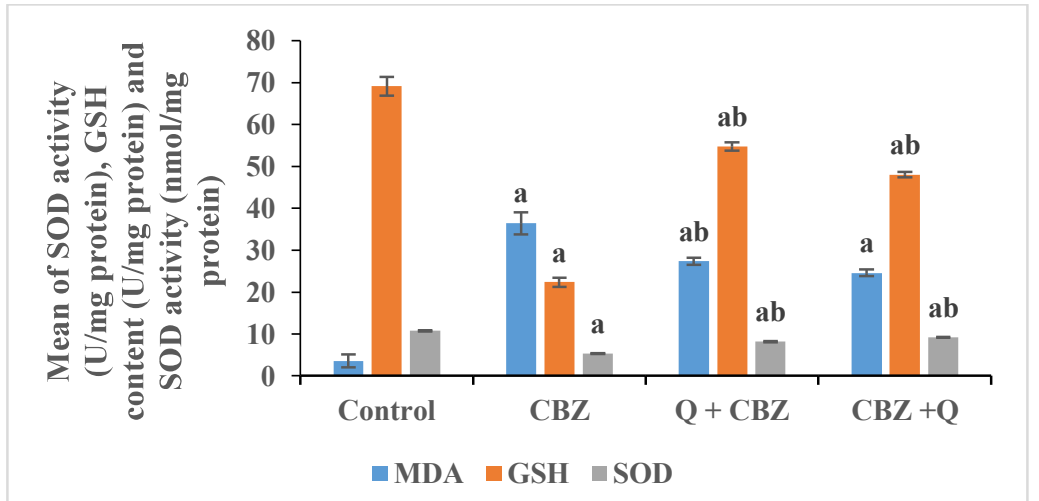

Fig.1: The effect of quercetin on SOD activity, GSH and MDA levels of normal and CBZ-treated rats. Data were expressed as Mean \pm S.E.M. and analyzed using one-way ANOVA followed by LSD test. Control, control group; CBZ: carbendazim model group; Q: quercetin group. a: compared with control group; b: compared with CBZ model group. 


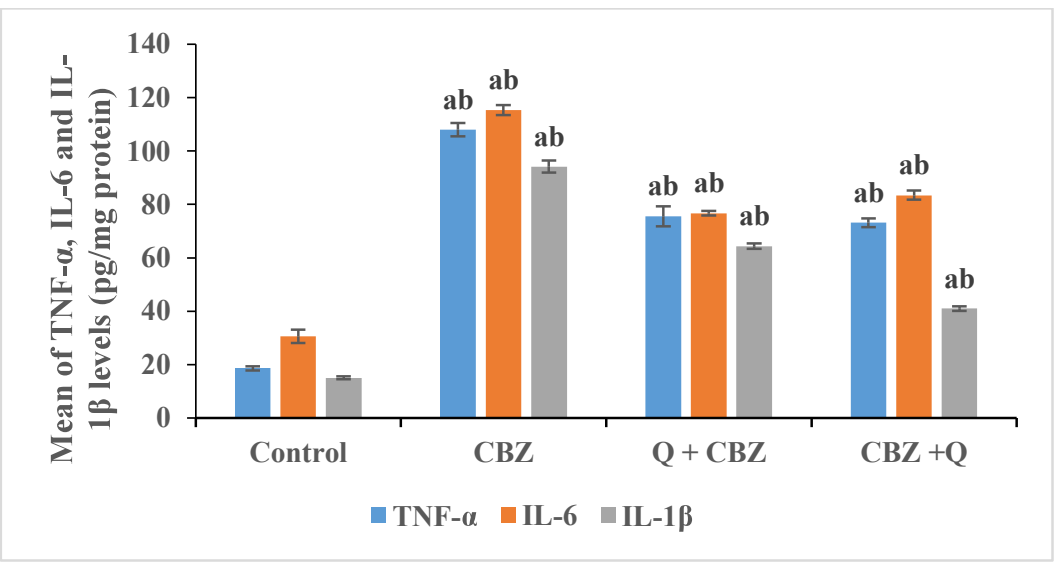

Fig.2: The effect of quercetin on TNF- $\alpha$, IL-6 and IL-1 $\beta$ levels of normal and CBZ-treated rats. Data were expressed as Mean \pm S.E.M. and analyzed using one-way ANOVA followed by LSD test. Control, control group; CBZ: carbendazim model group; Q: quercetin group. a: compared with control group; b: compared with CBZ model group.

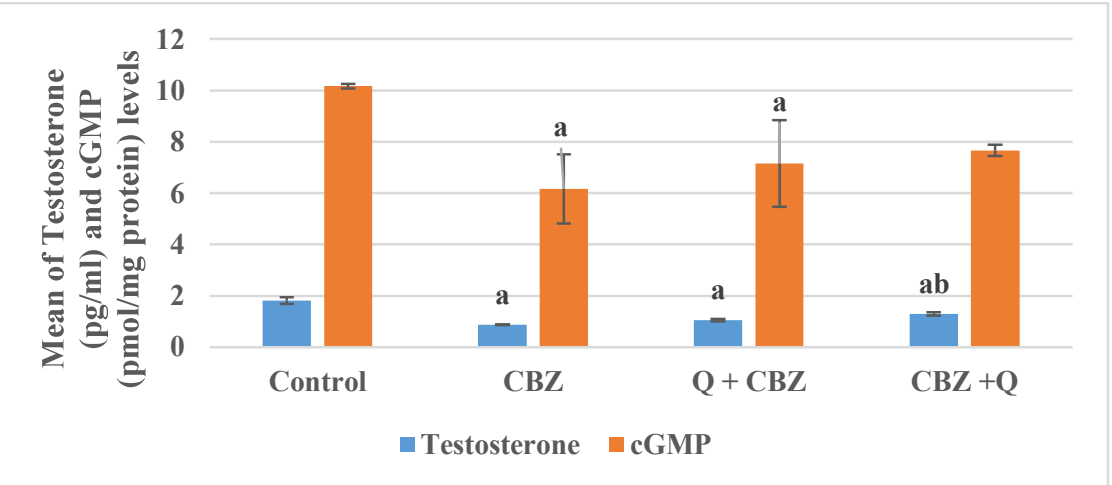

Fig.3: The Effect of quercetin on serum testosterone level and testicular cGMP level of normal and CBZtreated rats. Data were expressed as Mean \pm S.E.M. and analyzed using one-way ANOVA followed by LSD test. Control, control group; CBZ: carbendazim model group; Q: quercetin group. a: compared with control group; b: compared with CBZ model group.

\section{Results of histological study of testes:}

\section{Normal control group}

No histopathological changes were detected in the examined livers of hepatocytes, central veins and portal areas. The testes showed and testes of these rats. The liver showed normal histological appearance seminiferous tubules lined by normal germinal epithelium with active spermatogenesis and presence of spermatozoa in the lumen (Fig4) .

\section{Carbindazim administrated group:}

The testes of the treated rats revealed marked congestion of the subcapsular and interstitial blood vessels (Fig..9). 3The testicular interstitium was expanded by homogenous eosinophilic material (edema)). Multifocally, the lining epithelial cells of some seminiferous tubules exhibited degeneration characterized by swollen pale discrete large vacuoles, usually replaced the cytoplasm and occasionally accompanied by reduced spermatogenesis and absence of spermatozoa 
in the lumen. Rarely, degenerated tubules showed exfoliated epithelial cells in their lumen (Fig5).

\section{Rats treated with Quercetin for 2 weeks} followed by carbindazim for 6 weeks group:

The testes of the treated rats revealed congestion of the testicular blood vessels and interstitial capillaries. The interstitium was expanded by homogenous eosinophilic material (edema). Multifocally, the lining epithelial cells of large numbers of seminiferous tubules exhibited degeneration characterized by swollen pale vacuolated cytoplasm (Fig. 3.13); accompanied by reduced spermatogenesis and few spermatogenic giant cells in the lumen (Fig. 3.14). Rarely, marked testicular degeneration was observed in few seminiferous tubules with wavy and buckled basement membrane and

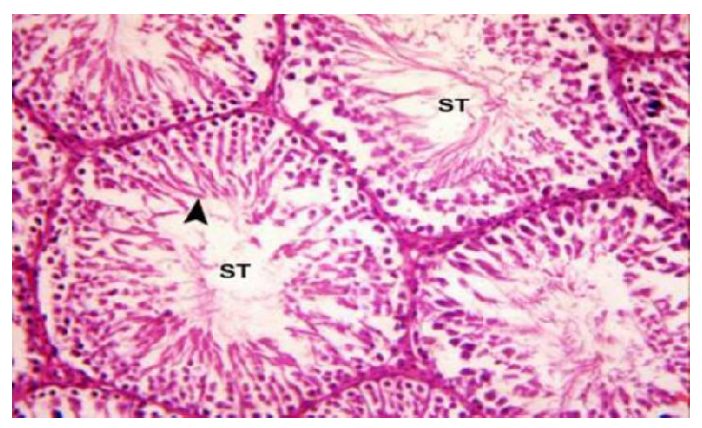

Fig. (4): Testis of control group I, showing normal histological appearance of seminiferous tubules (ST) with active spermatogenesis and presence of spermatozoa (arrowhead)in the lumen. H\&E stain x 200 lined by single layer of degenerated germ cells (Fig5). Occasionally, there were focal group of seminiferous tubules characterized by small size and lack of germ cells and spermatocytes and spermatids (Figs. 6).

\section{Rats treated with carbindazim for 6} weeks followed by Quercetin for $\mathbf{2}$ weeks:

The testes of the treated rats revealed congestion of the testicular blood vessels and interstitial homogenous eosinophilic material (edema). Multifocally, the lining epithelial cells of moderate numbers of seminiferous tubules exhibited degeneration characterized by swollen pale discrete cytoplasmic vacuoles, accompanied by reduced spermatogenesis and absence of spermatozoa in the lumen (Fig. 7). Rarely, spermatogenic giant cells were seen in the lumen of degenerated tubules.

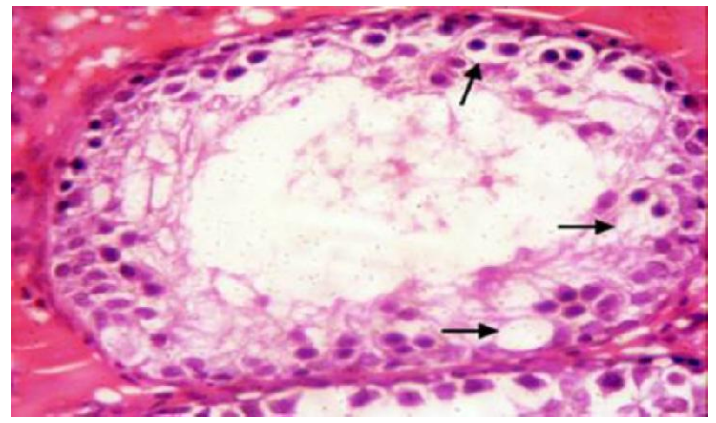

Fig. (5): Testis of rat treated with Carbindazim, showing degeneration of the lining epithelial cells of a seminiferous tubule characterized by swollen pale discrete large vacuoles (arrow) x 400. 


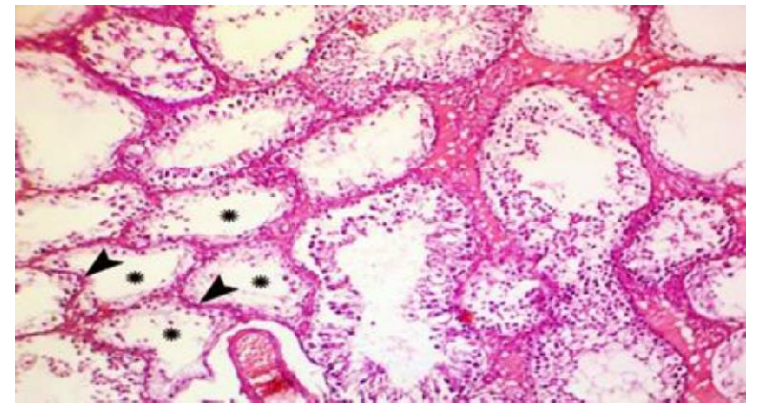

Fig. (6): Testis of rat treated Quercetin for 2 weeks followed by Carbindazim for 6 weeks, showing marked testicular degeneration in few seminiferous tubules (asterisk) with wavy and buckled basement membrane (arrowhead) and lined by single layer of degenerated germ cells. H\&E stain x 200

\section{DISCUSSION}

The present investigation demonstrated the protective

potential of quercetin against CBZ-induced testicular damage in rats. Carbendazim is a toxic substance according to the World Health Organization classification, which is broadly used as a fungicide agent [Prakash et al., 2013]. It acts on tubulin via interferes in microtubule development and meiotic cell division [Prakash et al., 2013]. Man may be exposed to carbendazim either through environmental contamination or through occupational exposures. Several diseases such as hypertension, eyes, nose and throat irritation and headache were reported due to occupational exposure [Can and Albertini, 1997; Barlas et al., 2002]. Carbendazim and related metabolite benomyl were identified to

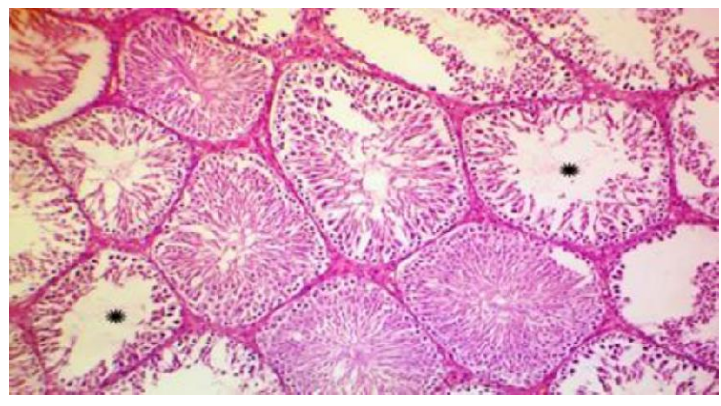

Fig. (7): Testis of rat treated with Carbindazim for 6 weeks followed by Quercetin for 2 weeks, showing degeneration of the lining epithelial cells of moderate numbers of seminiferous tubules, accompanied by reduced spermatogenesis and absence of spermatozoa in the lumen (asterisk). H\&E stain x 200.

cause toxicity of testicular via immature spermatids [Hess et al., 1991] and interference of microtubule association. There have recently been published numerous reports on the capabilities of fungicides to induce hematotoxicity, hepatotoxicity, and cytogenetic effects on human and animal chromosomes through enhancement of reactive oxygen species (ROS) production and thereby causing oxidative stress by reacting with macromolecules such as lipid, protein, and DNA resulting in cell dysfunction and DNA damage (Hashem, 2012). Therefore, the use of herbal plants such as quercetin with antioxidant and free radical scavenging properties is imperative in mitigating such problems. In the present study, we showed that administration of CBZ to rats caused a significant increase in MDA content 
and decrease in SOD activity. This can be explained by the fact that Fungicides eventually cause DNA damage due to the elevated MDA content and depleting the antioxidant enzymes (superoxide dismutase, SOD and catalase, CAT) activities (Bertram and Hass 2008; Calviello et al. 2006; Srivastava et al. 2012). The present results are in compliance with the earlier reports (Castro et al. 1997; Srivastava et al. 2012; Mahboub and Lamfon 2013; Goldoni et al. 2014; Yahia et al. 2015).

The oxidative damage of carbendazim on blood was indicated in our study by the higher MDA stages; lipid peroxidation generation, together with lower content of GSH activity in blood treated with carbendazim related to natural control. According to Sakr (2007), mancozeb fungicide in albino rats caused a significant reduces like an antioxidant enzyme in the tissue superoxide dismutase and an enhancement in lipid peroxidation (Halliwell and Gutteridge, 1989). The enhancement in lipid peroxidation indicates the oxidative pressure production, which is an imbalance between the independent radical's generation and the body defense system (Abdollahi et al., 2004).

GSH is the critical non-protein sulfhydryl antioxidant in the cell. In the estimation of oxidative pressure, glutathione concentration is a good marker [Asensi et al., 1999]. Similar to the current study, blood GSH concentration was significantly decreased that can be because of an increased utilization by
Glutathione peroxidase (Beutler, 1989). Glutathione is a tripeptide, which is concentrated in erythrocytes. Glutathione has different functions including the cell cycle regulation and gene expression and play a part in xenobiotics and eicosanoids metabolism (Bergelson et al., 1994). The increase in lipid peroxidation in carbendazim treated rats, beside the decrease in GSH concentration is suggestive of oxidative stress. This finding is parallel to many researchers (Prakash et al., 2013).

The cytokines and chemokines secreted by immune cells, play vital roles in regulating immune and inflammatory responses (Sieger et al., 2009; Trede et al., 2004). Previous reports have demonstrated that the transcription of innate immune-related genes can be induced or suppressed by environmental chemicals (Eder et al., 2008; Jin et al., 2011; Pressley et al., 2005). In accordance with the results of Jiang et al., 2015 whom showed that the mRNA levels of cytokines and chemokines, including IL-1 $\beta$, IL-6, and TNF- $\alpha$, were significantly induced after exposure to different concentrations of carbendazim for $8 \mathrm{~d}$, and most of the genes were up-regulated after the treatment with 4 $\mathrm{lg} / \mathrm{L}$ carbendazim, indicated that carbendazim might regulate the immune response during larval development.

The present study showed that proinflammatory biomarker like IL-6, IL-1 $\beta$ and TNF- $\alpha$ level were markedly elevated, indicating the development of the 
inflammation. The above CBZ-induced changes were significantly ameliorated by the QR treatment. Present data revealed the significant decreased in serum testosterone levels of CBZ-treated rats compared to control animals. In accordance with Rehnberg et al. (1989) described increased testosterone levels as well as expression of androgen binding protein $(A B P)$ in the testis without alteration of the plasmatic levels of this hormone. These authors suggest that disruption of testicular blood flow by CBZ may have influenced the distribution of testosterone. Another possible explanation would be that the increased availability of ABP could have trapped testosterone inside the testis. Treatment with QR $(50 \mathrm{mg} / \mathrm{kg} /$ day) to diabetic rats for 5 consecutive weeks corrected the testosterone levels compared to CBZ-treated rats. These results are in agreement with earlier reports that, QR treatment enhanced the testosterone levels in diabetic animals (Khaki et al., 2010; Tang et al., 2008).

Flavonoids are known to improve erectile function by their antioxidant and antiinflammatory properties (Zhang et al., 2013; Yang et al., 2012). In present study, treatment with Q to CBZ-treated rats improved the cGMP levels in testicular tissue as compared to untreated CBZ-treated rats, this may justify by its pharmacological potentials. In the current study, the biochemical data were confirmed by the histopathological alterations observed in the liver section of CBZ-treated group which showed congestion of hepatic blood vessels, dilated portal area, perivascular fibrosis and mononuclear cell infiltration, and proliferated bile ductile with cholestasis and fibroplasia. These findings are in support of Zari and AlAttar (2011), El-Damaty et al. (2012), and Mahboub and Lamfon (2013).

\section{Conclusion}

Present data revealed that Quercetin attenuates experimentally induced testicular damage rats. $Q$ rehabilitated the activities of the antioxidant enzymes, down-regulated the levels of LPO biomarker MDA and improving CBZ-induced testicular damage.

\section{REFERENCES}

Abdollahi M, Ranjbar A, Shadnia S, Nikfar S and Rezaie A 2004. Pesticides and oxidative stress: a review. Med Sci Monit.; 10(6):RA141-147.

Adedara IA, Vaithinathan S, Jubendradass R, Mathur PP and Farombi EO (2013): Kolaviron prevents carbendazim-induced steroidogenic dysfunction and apoptosis in testes of rats. Environ Toxicol Pharmacol.; 35(3):444-453.

Akbarsha MA, Kadalmani B, Girija R, Faridha A and Hamid KS (2001): Spermatotoxic effect of carbendazim. Indian J. Exp. Biol.; 39: 921-924.

Asensi M, Sastre J, Pallardo FV, Lloret A, Lehner M, Garcia-de-la Asuncion J, Viña J (1999): Ratio of reduced to 
oxidized glutathione as indicator of oxidative stress status and DNA damage. Methods Enzymol; 299:267-276.

Barlas N, Selmanoglu G, Songur S, et al (2002): Biochemical and histopathological effect of carbendazim to rat male reproduction. Pesti.; 17:59-71.

Bergelson S, Pinckus $\mathrm{R}$ and Daniel V (1994): Intracellular glutathione regulates fos/ jun induction and activation of glutathione-Stransferase gene expression. Cancer Res.; 54:3640.

Bertram C and Hass R (2008): Cellular responses to reactive oxygen speciesinduced DNA damage and aging. Biol Chem.; 389(3):211-220.

Beutler E (1989): Nutritional and metabolic aspects of glutathione. Annu Rev Nutr.; 9:287-302.

Boots AW, Haenen GR and Bast A (2008): Health effects of quercetin: From antioxidant to nutraceutical. Eur J Pharmacol.; 585(2-3):325-337.

Boudina A, Emmelin C, Baaliouamer A, Grenier-Loustalot MF and Chovelon JM (2003): Photochemical behaviour of carbendazim in aqueous solution. Chemosphere.;50(5):649-655.
Brito AF, Ribeiro M, Abrantes AM, Pires AS, Teixo RJ, Tralhão JG and Botelho MF (2015): Quercetin in cancer treatment, alone or in combination with conventional therapeutics? Curr Med Chem.; 22(26):3025-3039.

Calviello G, Piccioni E, Boninsegna A, Tedesco B, Maggiano N, Serini S, Wolf FI and Palozza P (2006): DNA damage and apoptosis induction by the pesticide mancozeb in rat cells: involvement of the oxidativemechanism. Toxicol Appl Pharmacol.; 211(2):87-96.

Can A and Albertini DF (1997): Stage specific effects of carbendazim (MBC) on meiotic cell cycle progression in mouse oocytes. Mol Reprod Dev.; 46(3):351-362.

Carlsen E, Giwercman A, Keiding $\mathrm{N}$ and Skakkebaek NE (1992): Evidence for decreasing quality of semen during past 50 years. BMJ.;305(6854):609613.

Carter SD, Hess RA and Laskey JW (1987):

The fungicide methyl 2benzimidazole carbamate causes infertility inmale Sprague-Dawley rats. Biol Reprod.; 37(3):709-717.

Castro S, Vinocur M, Permigiani M, Halle C, Taurian T and Fabra A (1997): 
Interaction of the fungicide Mancozeb and Rhizobium sp. in pure culture and under field conditions. Biol Fertil Soil; 25:147-151.

Chen B, He T, Xing Y and Cao T (2017): Effects of quercetin on the expression of MCP-1, MMP-9 and VEGF in rats with diabetic retinopathy. Exp Ther Med.; 14(6):6022-6026.

Chiu YH, Afeiche MC, Gaskins AJ, Williams PL, Petrozza JC, Tanrikut C, Hauser R and Chavarro JE (2015): Fruit and vegetable intake and their pesticide residues in relation to semen quality among men from a fertility clinic. Hum Reprod.; 30(6):13421351

De Souza RF and De Giovani WF (2004): Antioxidant properties of complexes of flavonoids with metal ions. Redox Report; 9(2): 97-104.

Eder KJ, Clifford MA, Hedrick RP, Kohler HR, Werner I (2008): Expression of immune-regulatory genes in juvenile Chinook salmon following exposure to pesticides and infectious hematopoietic necrosis virus (IHNV). Fish Shellfish Immunol.; 25(5):508516.

Eisenberg ML, Li S, Behr B, Cullen MR, Galusha D, Lamb DJ and Lipshultz LI (2014): Semen quality, infertility and mortality in the USA. Hum Reprod.; 29(7):1567-1574.

El-Damaty EMA, Farrag AH, Rowayshed G and Fahmy HM (2012): Biochemical and histopathological effects of systemic pesticides on some functional organs of male albino rats. J of Appl Sci Res; 8(11):5459-5469.

Farag A, Ebrahim H, ElMazoudy R and Kadous E (2011): Developmental toxicity of fungicide carbendazim in female mice. Birth Defects Res B Dev Reprod Toxicol.;92(2):122-130.

Geoffroy-Siraudin C, Loundou AD, Romain F, Achard V, Courbiere B, Perrard M, Durand P and Guichaoua M (2012): Decline of semen quality among 10 932 males consulting for couple infertility over a 20-year period in Marseille, France. Asian J Androl.;14(4):584-590.

Goldoni A, Klauck CR, Da Silva ST, Da Silva MD, Ardenghi PG and Da Silva LB (2014): DNA damage in wistar rats exposed to dithiocarbamate pesticide mancozeb. Folia Biologica (Praha); 60:202-204.

Grande F, Parisi OI, Mordocco RA, Rocca C, Puoci F, Scrivano L, Quintieri AM, Cantafio P, Ferla S, Brancale A, Saturnino C, Cerra MC, Sinicropi MS and Angelone T (2016): Quercetin 
Assessment of protective potential of Quercitin against carbendazim-induced testicular damage in male rats

derivatives as novel antihypertensive agents: Synthesis and physiological characterization. Eur J Pharrm Sci; 82: 161-170.

Guo Y, Meng XZ, Tang HL and Zeng EY (2008): Tissue distribution of organochlorine pesticides in fish collected from the Pearl River Delta, China: implications for fishery input source and bioaccumulation. Environ. Pollut.; 155, 150-156.

Halliwell B and Gutteridge JMC (1989): Free Radicals in Biology and Medicine, 2nd edn., Clarendon Press, Oxford.

Hashem HE (2012): Light and electron microscopic study of the possible protective effect of Nigella sativa on metalaxyl induced hepatotoxicity in adult albino rats. J Cell Sci Ther; $3: 118$

Hess RA, Moore BJ, Forrer J, Linder RE and Abuel-Atta AA (1991): The fungicide benomyl (methyl 1(butylcarbamoyl)-2benzimidazolecarbamate) causes testicular dysfunction by inducing the sloughing of germ cells and occlusion of efferent ductules. Fundam Appl Toxicol.; 17(4):733-745.

Iskender H, Dokumacioglu E, Sen TM, Ince I, Kanbay Y and Saral S (2017): The effect of hesperidin and quercetin on oxidative stress, NF- $\mathrm{\kappa B}$ and SIRT1 levels in a STZ-induced experimental diabetes model. Biomed Pharmacother.; 90:500-508.

Jensen TK, Jacobsen R, Christensen K, Nielsen NC and Bostofte E (2009): Good semen quality and life expectancy: a cohort study of 43,277 men. Am J Epidemiol.; 170(5):559565.

Jiang J, Wu S, Wang Y, An X, Cai L, Zhao $\mathrm{X}$ and $\mathrm{Wu} \mathrm{C}$ (2015): Carbendazim has the potential to induce oxidative stress, apoptosis, immunotoxicity and endocrine disruption during zebrafish larvae development. Toxicol In Vitro.; 29(7):1473-1481.

Jin Y, Zheng S and Fu Z (2011): Embryonic exposure to cypermethrin induces apoptosis and immunotoxicity in zebrafish (Danio rerio). Fish Shellfish Immunol.; 30(4-5):1049-1054.

Jollow DJ, Mitchell JR, Zampaglione N and Gillette JR (1974): Bromobenzeneinduced liver necrosis. Protective role of glutathione and evidence for 3,4bromobenzene oxide as the hepatotoxic metabolite. Pharmacology.; 11(3):151-169.

Khaki A, Fathiazad F, Nouri M, Khaki A, Maleki NA, Khamnei HJ and Ahmadi 
P (2010): Beneficial effects of quercetin on sperm parameters in streptozotocin-induced diabetic male rats. Phytother Res.; 24(9):12851291.

Le Moal J, Rolland M, Goria S, Wagner V, De Crouy-Chanel P, Rigou A, De Mouzon J and Royère D (2014): Semen quality trends in French regions are consistent with a global change in environmental exposure. Reproduction.;147(4):567-574.

Lewandowska A and Walorczyk S (2010): Carbendazim residues in the soil and their bioavailability to plants in four successive harvests. Pol. J. Environ. Stud.; 19: 757-761.

Liu W, Zhang M, Feng J, Fan A, Zhou Y and $\mathrm{Xu}$ Y (2017): The Influence of Quercetin on Maternal Immunity, Oxidative Stress, and Inflammation in Mice with Exposure of Fine Particulate Matter during Gestation. Int $\mathrm{J}$ Environ Res Public Health; 14(6):592.

Ludwikowska A, Bojarski B, Socha S and Lutnicka H (2013): The effect of carbendazim on embryonic Prussian carp (Carassius gibelio) development and hatching. Arch. Pol. Fish.; 21: 367-371.
Mahboub FA and Lamfon HA (2013): Protective effect of Gingo biloba extract on carbendazim-induced hepatotoxicity in albino rats. Food and Nutr Sci; 4:866-872.

Mantovani A, Maranghi F, Ricciardi C, Macrì C, Stazi AV, Attias L and Zapponi GA (1998): Developmental toxicity of carbendazim: comparison of no-observed-adverse-effect level and benchmark dose approach. Food Chem Toxicol.;36(1):37-45.

Marunaka Y (2017): Actions of quercetin, a flavonoid, on ion transporters: its physiological roles. Ann N Y Acad Sci.; 1398(1):142-151.

Mehrpour O, Karrari P, Zamani N, Tsatsakis AM and Abdollahi M (2014): Occupational exposure to pesticides and consequences on male semen and fertility: a review. Toxicol Lett.; 230(2):146-156.

Morinaga H, Yanase T, Nomura M, Okabe T, Goto K, Harada N and Nawata $\mathrm{H}$ (2004): A benzimidazole fungicide, benomyl, and its metabolite, carbendazim, induce aromatase activity in a human ovarian granulose-like tumor cell line (KGN). Endocrinology;145(4):1860-1869.

Nishimura Fde C, de Almeida AC, Ratti BA, Ueda-Nakamura T, Nakamura CV, 
Ximenes VF and Silva Sde O (2013):

Antioxidant effects of quercetin and naringenin are associated with impaired neutrophil microbicidal activity. Evid Based Complement Alternat Med; 2013: 795916.

Ohkawa H, Ohishi N and Yagi K (1979): Assay for lipid peroxidase in animal tissue by thiobarbituric acid reaction. Anal Biochem.; 95(2):351-358.

Palanikumar L, Kumaraguru AK, Ramakritinan $\mathrm{CM}$ and Anand $\mathrm{M}$ (2014): Toxicity, biochemical and clastogenic response of chlorpyrifos and carbendazim in milk fish Chanos chanos. Int. J. Environ. Sci. Technol.; 11: 765-774.

Phan TT, Lim IJ, Chan SY, Tan EK, Lee ST and Longaker MT (2004): Suppression of transforming growth factor beta/smad signaling in keloidderived fibroblasts by quercetin: implications for the treatment of excessive scars. J Trauma.; 57(5):1032-1037.

Prakash N, Waghe P, Lokesh LV, Pavithra BH, Ashok P and Girish MH (2013): Curcumin Ameliorate Carbendazim Induced Toxicopathological Changes In Male Wistar Rats. International Journal of Pharmacology \& Toxicology Science.; 3(1):22-31.
Pressley ME, Phelan PE 3rd, Witten PE, Mellon MT and Kim CH (2005): Pathogenesis and inflammatory response to Edwardsiella tarda infection in the zebrafish. Dev Comp Immunol.; 29(6):501-513.

Rehnberg GL, Cooper RL, Goldman JM, Gray LE, Hein JF and McElroy WK (1989): Serum and testicular testosterone and androgen binding protein profiles following subchronic treatment with carbendazim. Toxicol Appl Pharmacol.; 101(1):55-61.

Rest RF and Spitznagel JK (1977): Subcellular distribution of superoxide dismutase in human neutrophils. Influence of myleoperoxide on the measurement of superoxide dismutase activity. Biochemical Journal; 166:145-153.

Rivera Rivera A, Castillo-Pichardo L, Gerena $\mathrm{Y}$ and Dharmawardhane $\mathrm{S}$ (2016): Anti-Breast Cancer Potential of Quercetin via the Akt/AMPK/Mammalian Target of Rapamycin (mTOR) Signaling Cascade. PLoS One.; 11(6): e0157251.

Roslan J, Giribabu N, Karim K and Salleh N (2017): Quercetin ameliorates oxidative stress, inflammation and apoptosis in the heart of 
streptozotocin-nicotinamide-induced adult male diabetic rats. Biomed Pharmacother; 86: 570-582.

Sakr SA (2007): Ameliorative effect of ginger (Zingiberofficinale) on mancozeb fungicide induced liver injury in Albino Rats. Australian J Basic ApplSci.; 14:650-656.

Selmanoglu G, Barlas N, Songur S and Kockaya EA (2001): Carbendaziminduced haematological, biochemical and histopathological changes to the liver and kidney of male rats. Hum. Exp. Toxicol.; 20, 625-630.

Sieger D, Stein C, Neifer D, van der Sar AM and Leptin M (2009): The role of gamma interferon in innate immunity in the zebrafish embryo. Dis Model Mech.; 2(11-12):571-581.

Singh S, Singh N, Kumar V, Datta S, Wani AB, Singh D, Singh $K$ and Singh $J$ (2016): Toxicity, monitoring and biodegradation of the fungicide carbendazim. Environ. Chem. Lett.; 14(3): 317-329.

Songür SH, Koçkaya EA, Selmanoĝlu G and Barlas N (2005): Dose-dependent effects of carbendazim on rat thymus cell biochemistry and function. Cell Biochem Funct; 23: 457-460.

Srivastava AK, Ali W, Singh R, Bhui K, Tyagi S, Al-Khedhairy AA,
Srivastava PK, Musarrat J and Shukla Y (2012): Mancozeb-induced genotoxicity and apoptosis in cultured human lymphocytes. Life Sci.; 90(21-22):815-824.

Tang XY, Zhang Q, Dai DZ, Ying HJ, Wang QJ and Dai Y (2008): Effects of strontium fructose 1,6-diphosphate on expression of apoptosis-related genes and oxidative stress in testes of diabetic rats. Int J Urol.; 15(3):251256.

Thipkaew C, Wattanathorn J, and Muchimapura S (2017): Electrospun nanofibers loaded with quercetin promote the recovery of focal entrapment neuropathy in a rat model of streptozotocin-induced diabetes. BioMed Research International; 2017: 12 .

Trede NS, Langenau DM, Traver D, Look AT and Zon LI (2004): The use of zebrafish to understand immunity. Immunity.; 20(4):367-379.

Wang L, Wang B, Li H, Lu H, Qiu F, Xiong L, Xu Y, Wang G, Liu X, Wu H and Jing H (2012): Quercetin, a flavonoid with anti-inflammatory activity, suppresses the development of abdominal aortic aneurysms in mice. Eur J Pharmacol.; 690(1-3):133-141. 